\title{
Clinical Outcomes of Proximal Gastrectomy versus Total Gastrectomy for Proximal Gastric Cancer: A Systematic Review and Meta-Analysis
}

\author{
Lulu Zhao $^{\text {a }}$ Rui Ling ${ }^{b}$ Jinghua Chen ${ }^{\text {a }}$ Anchen Shi ${ }^{c}$ Changpeng Chai ${ }^{d}$ \\ Fuhai Ma ${ }^{\mathrm{a}}$ Dongbing Zhao ${ }^{\mathrm{a}}$ Yingtai Chen ${ }^{\mathrm{a}}$ \\ ${ }^{a}$ National Cancer Center/National Clinical Research Center for Cancer/Cancer Hospital, Chinese Academy of \\ Medical Sciences and Peking Union Medical College, Beijing, China; ${ }^{b}$ Department of Microbiology and Immunology, \\ Georgetown University Medical Center, Washington, DC, USA; ${ }^{C}$ The Second Clinical Medical College of Lanzhou \\ University, Lanzhou University, Lanzhou, China; ${ }^{\mathrm{d} T h e}$ First Clinical Medical College of Lanzhou University/General \\ Surgery of the First Hospital of Lanzhou University, Lanzhou, China
}

\section{Keywords}

Proximal gastric cancer · Proximal gastrectomy · Total gastrectomy · Survival $\cdot$ Meta-analysis

\begin{abstract}
Introduction: The extent of optimal gastric resection for proximal gastric cancer (PGC) continues to remain controversial, and a final consensus is yet to be met. The current study aimed to compare the perioperative outcomes, postoperative complications, and overall survival (OS) of proximal gastrectomy $(\mathrm{PG})$ versus total gastrectomy (TG) in the treatment of PGC through a meta-analysis. Methods: We systematically searched PubMed, Embase, The Cochrane Library, and Web of Science for articles published in English since database establishment to October 2019. Evaluated endpoints were perioperative outcomes, postoperative complications, and long-term survival outcomes. Results: A total of 2,896 patients in 25 full-text articles were included, of which one was a prospective randomized study, one was a clinical phase III trial, and the rest were retrospective com-
\end{abstract}

parative studies. The PG group showed a higher incidence of anastomotic stenosis ( $\mathrm{OR}=2.21[95 \% \mathrm{Cl}: 1.08-4.50] ; p=0.03)$ and reflux symptoms $(\mathrm{OR}=3.33$ [95\% Cl: 1.85-5.99]; $p<$ 0.001 ) when compared with the TG group, while no difference was found in $\mathrm{PG}$ patients with double-tract reconstruction (DTR). The retrieved lymph nodes were clearly more in the TG group (WMD $=-10.46$ [95\% Cl: -12.76 to -8.17 ]; $p<$ $0.001)$. The PG group was associated with a better 5 -year OS relative to TG with 11 included studies (OR $=1.35[95 \%$ Cl: 1.03-1.77]; $p=0.03$ ). After stratification for early gastric cancer and PG with DTR groups, however, there was no significant difference between the 2 groups (OR $=1.35$ [95\% Cl: $0.59-2.45] ; p=0.62$ ). Conclusion: In conclusion, PG was associated with a visible improved long-term survival outcome for all irrespective of tumor stage, while a similar 5-year OS for only early gastric cancer patients between the 2 groups. Future randomized clinical trials of esophagojejunostomy techniques, such as DTR following PG, are expected to prevent postoperative complications and assist surgeons in the choice of surgical approach for PGC patients.

(c) 2020 S. Karger AG, Base karger@karger.com

www.karger.com/dsu

Karger' (c) 2020 S. Karger AG, Base

(1020 S. Karger AG, Basel
National Cancer Center/National Clinical Research Center for Cancer/Cancer Hospital Chinese Academy of Medical Sciences and Peking Union Medical College 17 Panjiayuan Nanli, Beijing 100021 (China)

yingtaichen@126.com 


\section{Introduction}

Gastric cancer remains a world-wide cancer with the third most frequent cause of cancer-related deaths [1]. Although the overall incidence of gastric cancer has been declining in some countries, the incidence of carcinoma of the proximal third of the stomach has been increasing at an alarming rate in recent years [2-4]. Consequently, the optimal surgical selection has received considerable attention for proximal gastric cancer (PGC).

To date, the optimal extent of gastric resection for PGC patients, that is, proximal gastrectomy (PG) or total gastrectomy (TG), remains controversial. Several studies have shown that PG was a considerable resection procedure that provided equivalent oncological outcomes compared with conventional TG, although more than half of these studies are defined as early PGC [5-18]. Proponents of TG, however, have argued that TG was associated with better overall survival (OS) as well as less postgastrectomy disturbances [19-21]. Definitely, most studies were too small to evaluate the surgical outcomes of PG adequately. Thus, the purpose of the current study was to compare the perioperative outcomes, postoperative complications, and OS of PG versus TG and the reconstruction types following PG procedure in the treatment of PGC, through a systematic review and meta-analysis of published studies.

\section{Methods}

Study Selection and Study Strategy

We systematically searched PubMed, Embase, The Cochrane Library, and Web of Science databases. The search strategy of PubMed was as follows and was applied to other databases also: ("proximal gastric cancer" [Tiab] OR "proximal gastric carcinoma" [Tiab] OR "PGC" [Tiab] OR "upper-third gastric adenocarcinoma" [Tiab] OR "upper-third gastric cancer" [Tiab] OR "proximal third gastric cancer" [Tiab] OR "adenocarcinoma of the upper third of the stomach" [Tiab] OR "cancer of the cardia and esophagogastric junction" [Tiab] OR "cancer of the cardia" [Tiab] OR "cardia adenocarcinoma" [Tiab]) AND ("proximal gastrectomy" [Tiab] OR "PG" [Tiab]) AND ("total gastrectomy" [Tiab] OR "TG" [Tiab]). All articles published in English since database establishment to October 2019 were included.

\section{Inclusion and Exclusion Criteria}

Inclusion criteria were described as follows: (1) studies that compared PG with TG for PGC; (2) human studies; (3) studies with at least one of the outcomes mentioned; (4) PG or TG that was performed with either laparoscopy-assisted or open gastrectomy; and (5) any type of comparative study. Excluded criteria were described as follows: (1) abstracts, letters, editorials, expert opinions, case reports, reviews, and studies lacking control groups;

(2) studies for benign lesions and gastrointestinal stromal tumors;

(3) studies including only subgroup analyses comparing PG with TG; (4) studies without necessary data for statistical analysis; and (5) duplicate research based on author or center.

Fig. 1 The flow diagram of the research

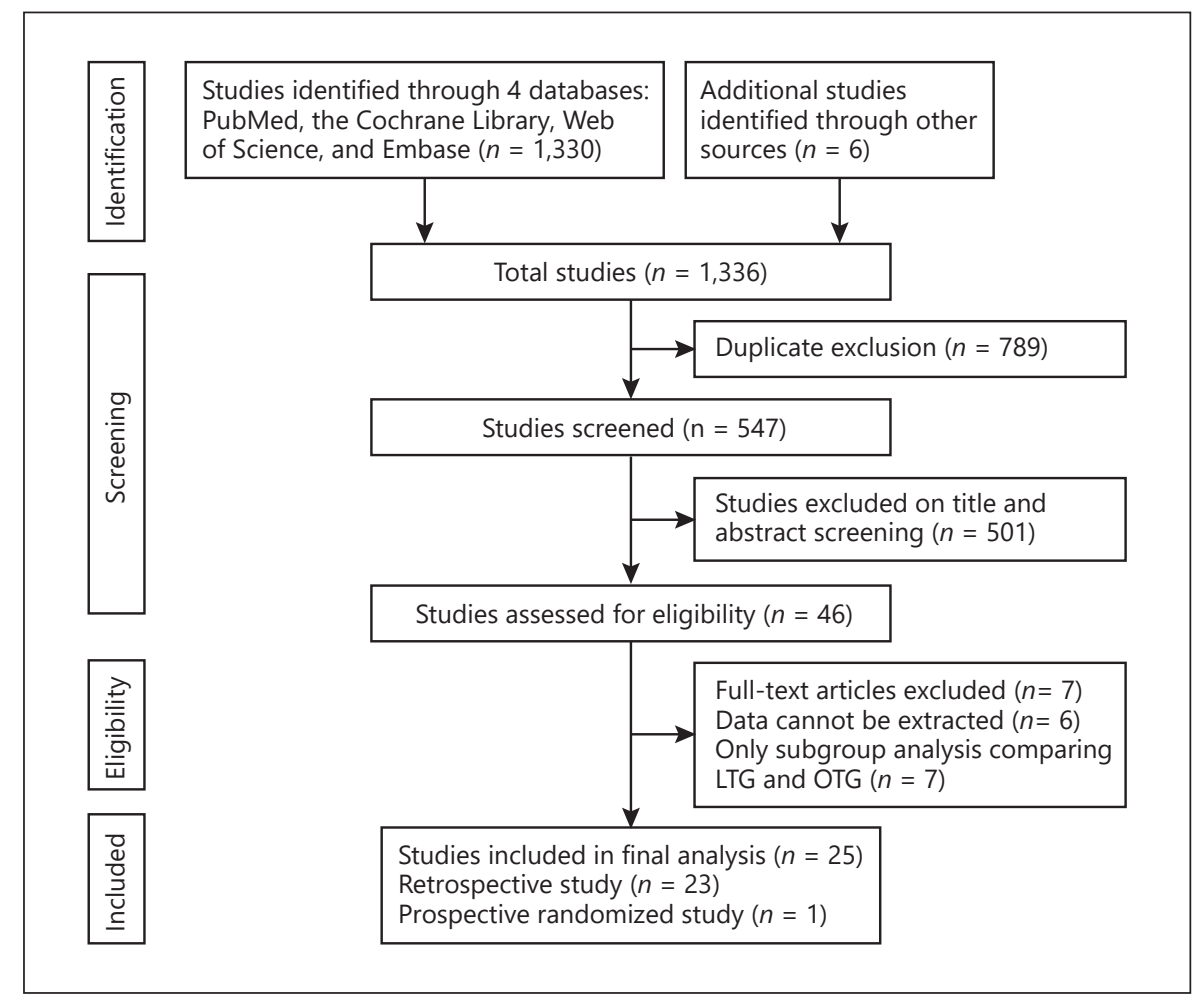
process until October 2019. 


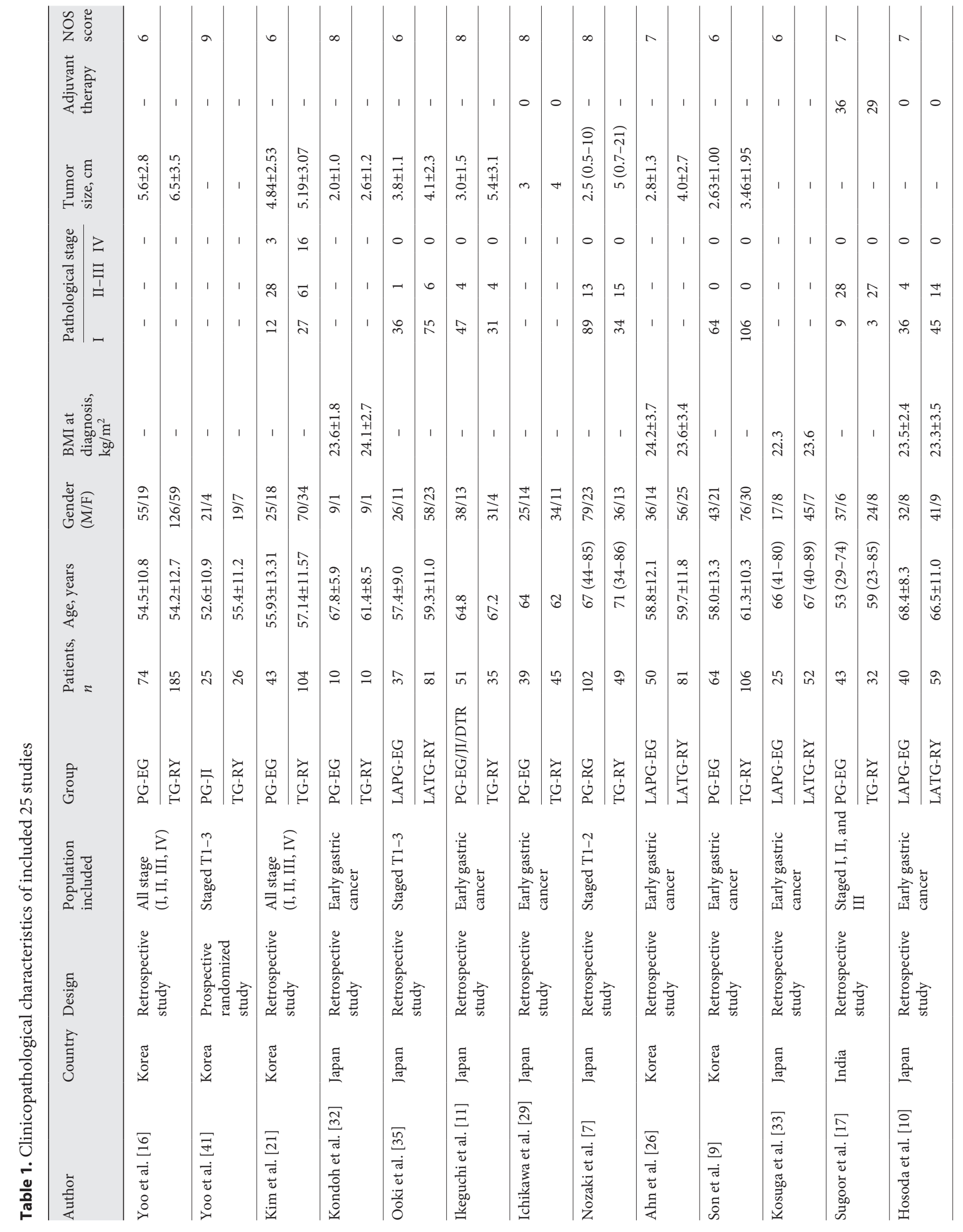




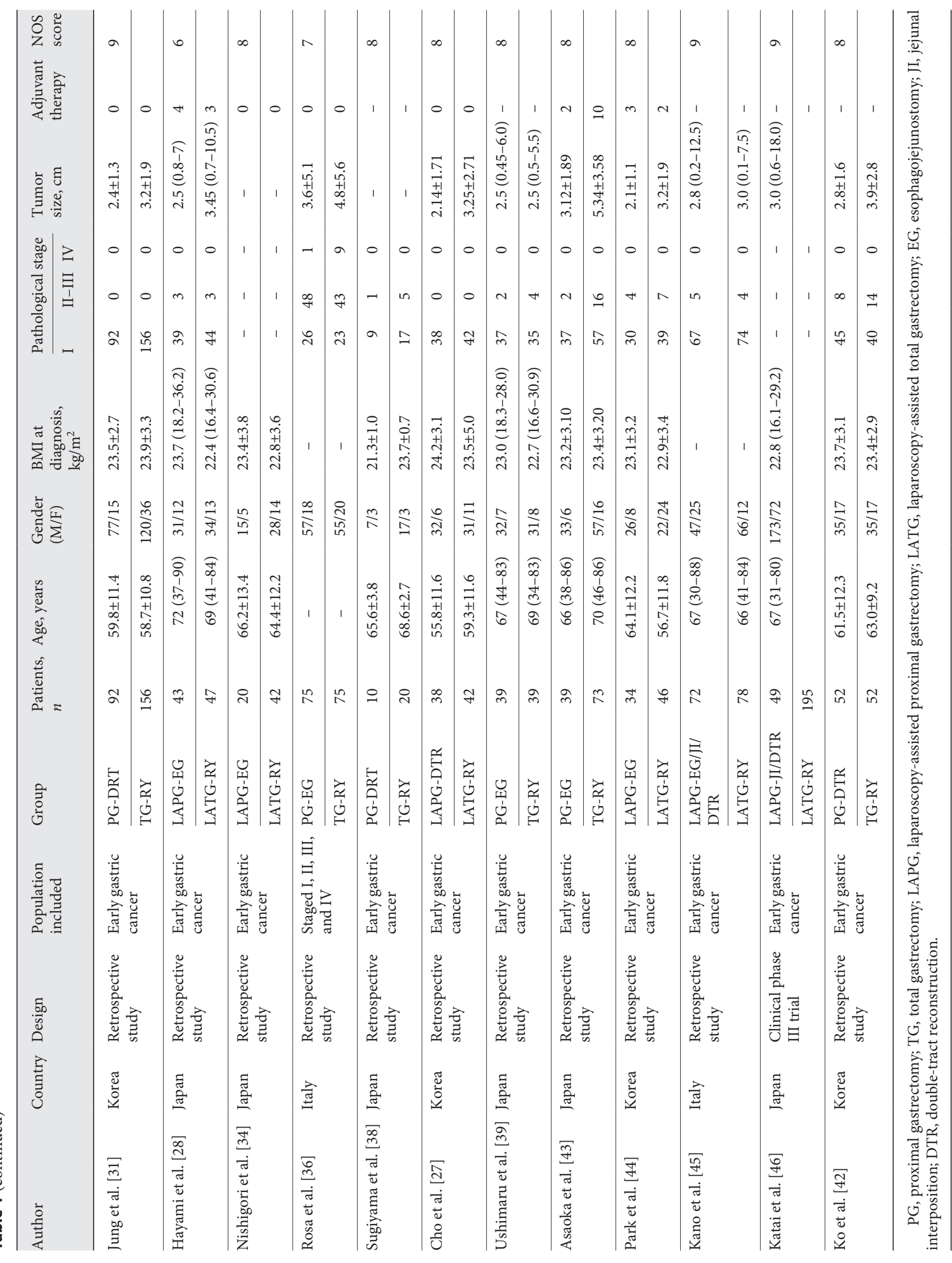


Table 2. Subgroup meta-analysis of comparison between PG and TG

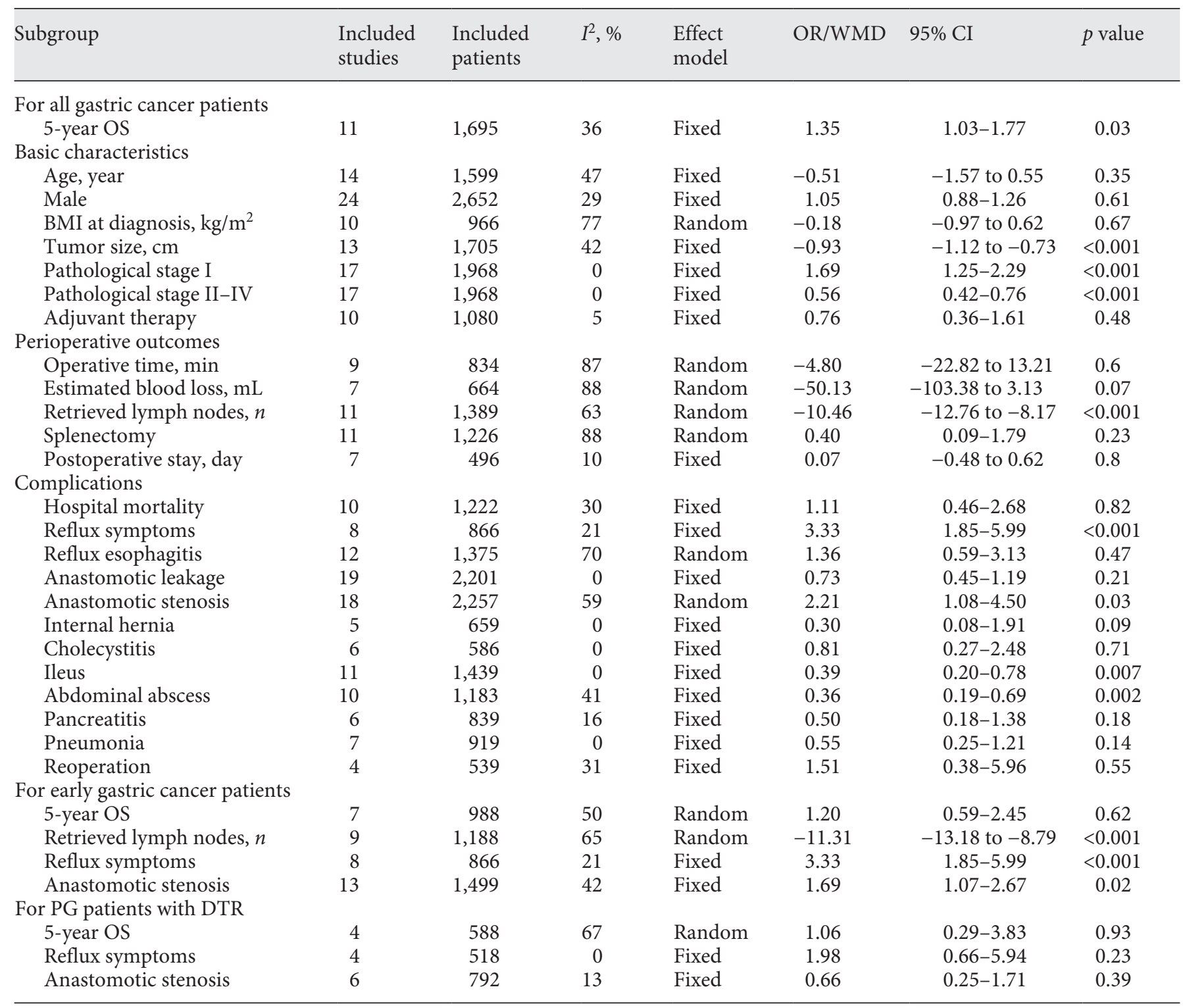

PG, proximal gastrectomy; TG, total gastrectomy; WMD, weighted mean difference; CI, confidence interval; OR, odds ratio; OS, overall survival; DTR, double-tract reconstruction.

\section{Quality Assessment of the Studies}

The Newcastle-Ottawa Quality Assessment Scale (NOS) was used to evaluate the quality of our included studies by 2 independent reviewers (Table 1) [22]. There were 9 elements in the NOS to assess patient population and selection, study comparability, follow-up, and outcome of interest. Each study was graded as either low quality (0-5) or high quality (6-9). A consensus reviewer resolved any discrepancies.

Data and Statistical Analysis

Effects were expressed as weighted mean difference (WMD) with corresponding 95\% confidence interval (CI) for continuous variables and odds ratio (OR) with corresponding 95\% CI for categorical variables. Heterogeneity was evaluated using the $\chi^{2}$ test, and $p$ value $<0.1$ was considered significant, while $I^{2}$ values were used for the evaluation of statistical heterogeneity [23]. Random effects models were used owing to the high heterogeneity of the studies; otherwise, fixed-effects models were used [24, 25]. Sensitivity analyses were performed by removing individual studies from the dataset and analyzing the effect on the overall results to identify sources of significant heterogeneity. Meta-analysis was performed using the Review Manager Version 5.3 software (The Cochrane Collaboration, Oxford, UK). A 2-tailed value of $p \leq 0.05$ was considered significant. 


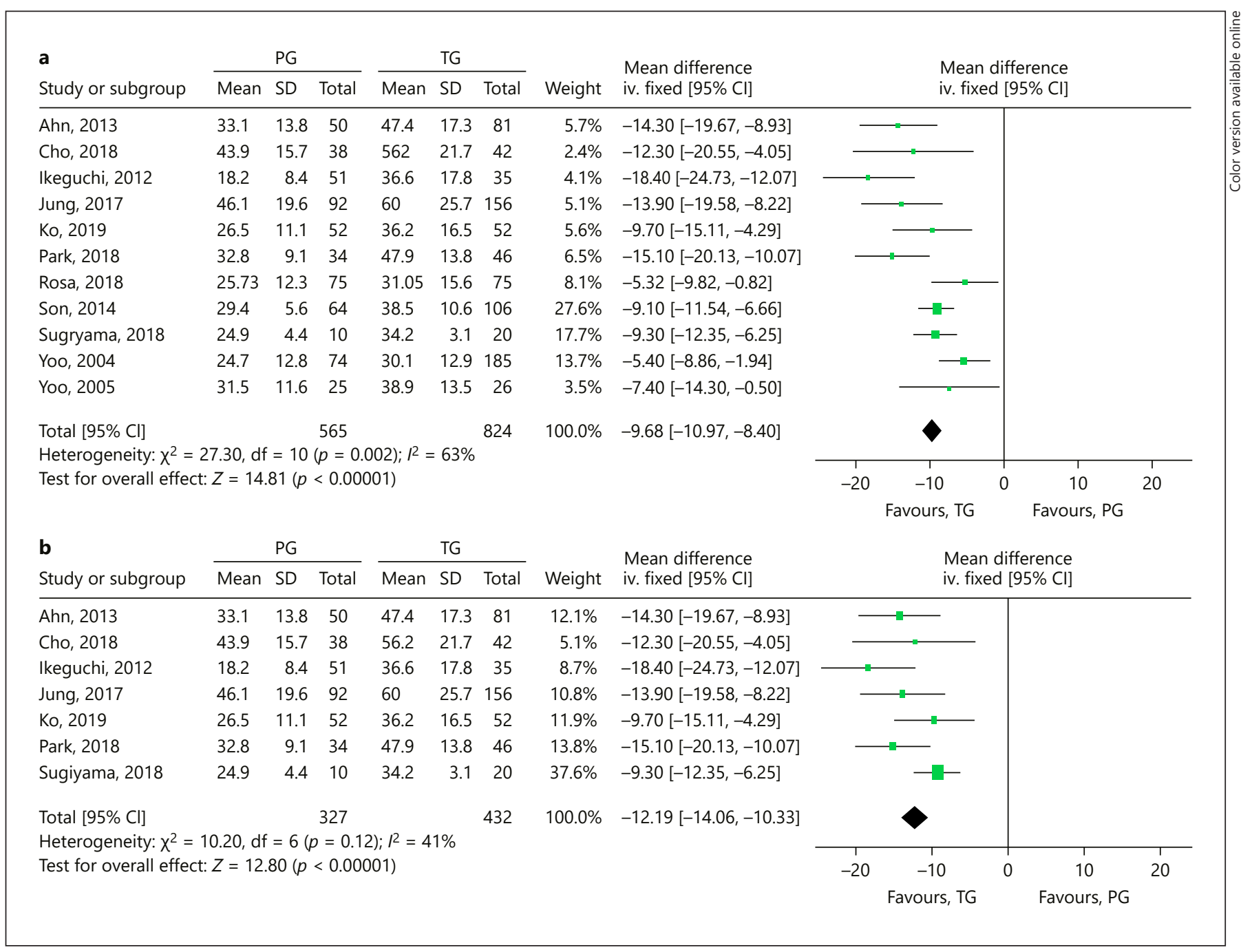

Fig. 2 The number of retrieved lymph nodes of gastrectomy between PG and TG groups. a For all gastric cancer patients irrespective of stage. b For only early gastric cancer patients. PG, proximal gastrectomy; TG, total gastrectomy.

After the meta-analyses for all included gastric cancer patients irrespective of tumor stage, we further analyzed 2 detailed subgroups: 1 group consisting of only early gastric cancer patients, and the other for only the PG group with double-tract reconstruction (DTR). Early gastric cancer was defined as clinical early gastric cancer or clinical stage I tumor as defined in the original studies.

\section{Results}

\section{Selected Studies}

Figure 1 shows the flow diagram of the research process. The search strategy generated 1,336 clinical studies mentioned PG versus TG for PGC. After screening the titles, abstracts, full-text, or a combination of these, we selected articles based on the inclusion and exclusion criteria. Finally, a total of 2,896 patients in 25 full-text articles [7, 9-11, 17, 21, 26-45] were identified for further investigation, of which one [40] was a prospective randomized study, one [45] was a clinical phase III trial, and the rest were retrospective comparative studies. Table 1 presents the characteristics and quality assessment scores of the included studies.

\section{Perioperative Outcomes}

There were 24 studies that provided information on surgery (Table 2; see online suppl. Table 1; for all online suppl. material, see www.karger.com/doi/10.1159/000506104). The meta-analysis showed that the operation time was 


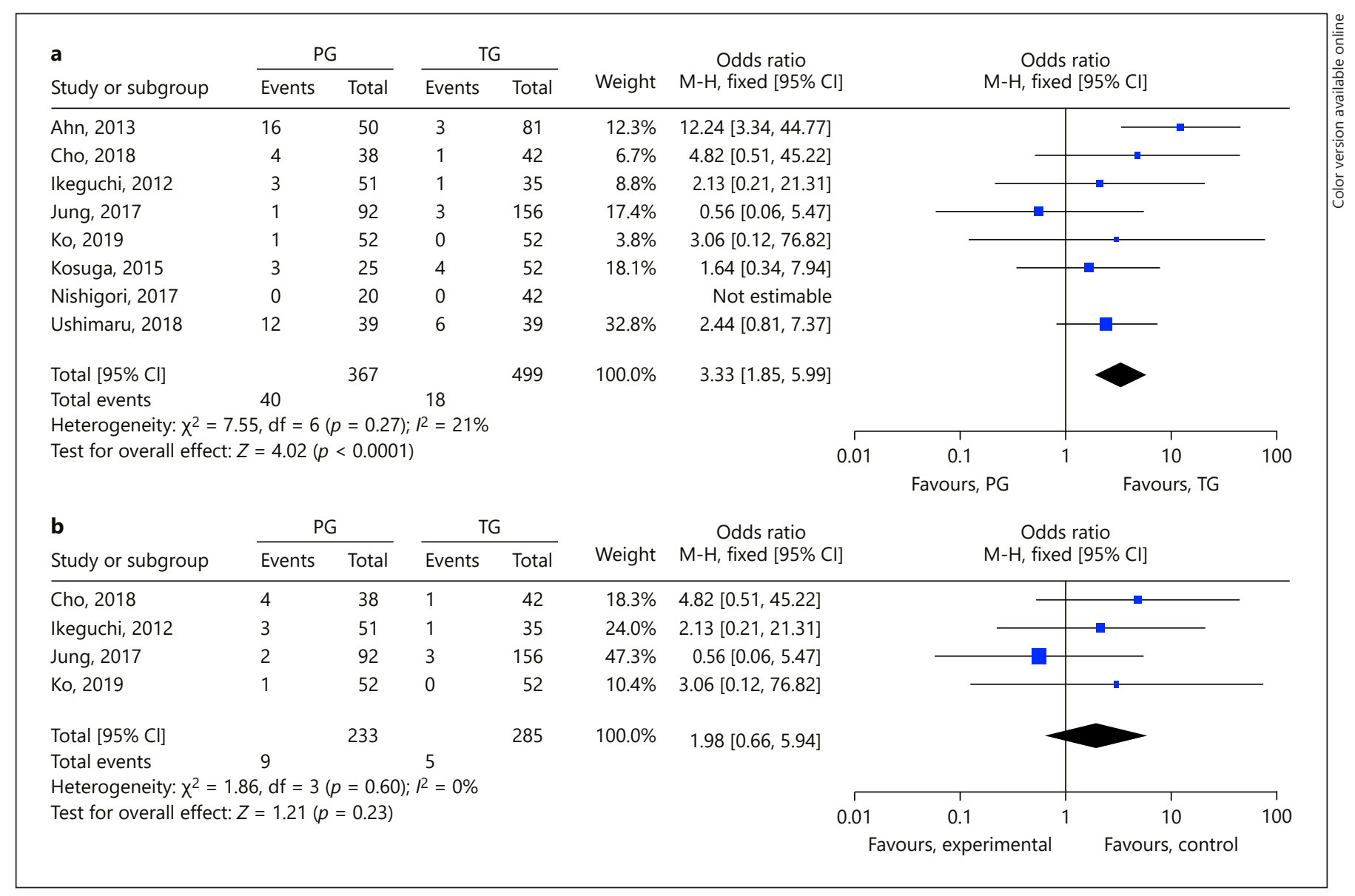

Fig. 3 The incidence of reflux symptoms of gastrectomy between the PG and TG groups. a For all gastric cancer patients, which were all studies of early gastric cancer patients. b For only the PG group with DTR. PG, proximal gastrectomy; TG, total gastrectomy; DTR, double-tract reconstruction.

comparable between the $\mathrm{PG}$ and $\mathrm{TG}$ groups $(\mathrm{WMD}=-4.80$ [95\% CI: -22.82 to 13.21 ]; $p=0.60$ ). The heterogeneity between the 2 groups was significant $\left(I^{2}=87 \%\right)$ (online suppl. Fig. 1). There was also no significant difference in the estimated blood loss during gastrectomy between the 2 groups (WMD $=-50.13$ [95\% CI: -103.38 to 3.13]; $p=0.07$ ) (online suppl. Fig. 2).

Eleven of the 25 studies reported the number of retrieved lymph nodes of the gastrectomy. The results showed that the harvested lymph nodes were more in the TG group than in the PG group (WMD $=-10.46[95 \%$ CI: -12.76 to -8.17 ]; $p<0.001)$. The heterogeneity between the 2 groups was also significant $\left(I^{2}=63 \%\right)$ (Fig. 2a). This benefit of retrieved lymph nodes for the TG procedure was also seen in the detailed groups for early gastric cancer patients (WMD $=-11.31$ [95\% CI: -13.18 to -8.79 ]; $p<0.001$ ) (Table 2; Fig. 2b).
Eleven studies showed the perioperative outcome of splenectomy. The meta-analysis revealed similar outcomes $(\mathrm{OR}=0.40$ [95\% CI: 0.09-1.79]; $p=0.23$ ) and significant heterogeneity between the PG and TG groups $\left(I^{2}=88 \%\right)$ (online suppl. Fig. 3 ). The fixed model $\left(I^{2}=\right.$ $10 \%)$ of postoperative stay showed no significant differences between the 2 groups (WMD $=0.07$ [95\% CI: -0.48 to 0.62 ]; $p=0.80$ ) (online suppl. Fig. 4).

\section{Postoperative Complications}

Table 2 and online suppl. Table 2 show the postoperative complications of the included 25 studies. Among these morbidities, there were no differences in the frequencies of hospital mortality, anastomotic leakage, internal hernia, cholecystitis, pancreatitis, pneumonia, and reoperation $(p>0.05)$. 


\begin{tabular}{|c|c|c|c|c|c|}
\hline \multirow{2}{*}{$\begin{array}{l}\text { a } \\
\text { Study or subgroup }\end{array}$} & \multicolumn{2}{|c|}{ PG } & \multicolumn{2}{|c|}{ TG } & \multirow[b]{2}{*}{ Weight } \\
\hline & Events & Total & Events & Total & \\
\hline Ahn, 2013 & 6 & 50 & 4 & 81 & $8.3 \%$ \\
\hline Cho, 2018 & 0 & 38 & 2 & 42 & $3.7 \%$ \\
\hline Hayami, 2017 & 2 & 43 & 6 & 47 & $7.1 \%$ \\
\hline Hosoda, 2016 & 11 & 40 & 5 & 59 & $8.9 \%$ \\
\hline Ikeguchi, 2012 & 0 & 51 & 3 & 35 & $3.8 \%$ \\
\hline Jung, 2017 & 3 & 92 & 2 & 156 & $6.7 \%$ \\
\hline Katai, 2019 & 0 & 49 & 0 & 195 & $4.1 \%$ \\
\hline Kim, 2006 & 20 & 43 & 0 & 104 & $6.1 \%$ \\
\hline Ko, 2019 & 2 & 52 & 2 & 52 & $\begin{array}{l}6.1 \% \\
8.0 \%\end{array}$ \\
\hline Kosuga, 2015 & 4 & 25 & 5 & 52 & $\begin{array}{l}8.0 \% \\
3.0 \%\end{array}$ \\
\hline Nishlgori, 2017 & 5 & 20 & 0 & 42 & $3.9 \%$ \\
\hline Nozaki, 2013 & 6 & 102 & 0 & 49 & $4.0 \%$ \\
\hline Rosa, 2018 & 5 & 75 & 1 & 75 & $5.6 \%$ \\
\hline Son, 2014 & 1 & 64 & 3 & 106 & $5.3 \%$ \\
\hline Sugiyama, 2018 & 0 & 10 & 1 & 20 & $3.3 \%$ \\
\hline Ushimaru, 2018 & 6 & 39 & 1 & 39 & $5.6 \%$ \\
\hline Yoo, 2004 & 26 & 74 & 15 & 185 & $10.4 \%$ \\
\hline Yoo, 2005 & 1 & 25 & 3 & 26 & $5.2 \%$ \\
\hline Total $[95 \% \mathrm{Cl}]$ & & 892 & & 1,365 & $100.0 \%$ \\
\hline Total events & 98 & & 53 & & \\
\hline \multicolumn{6}{|c|}{$\begin{array}{l}\text { Heterogeneity: } \tau^{2}=1.13, \chi^{2}=39.00, \mathrm{df}=16(p=0.001) ; R^{2}=59 \% \\
\text { Test for overall effect: } Z=2.18(p=0.03)\end{array}$} \\
\hline
\end{tabular}

Odds ratio

Odds ratio

random $[95 \% \mathrm{Cl}]$

$\mathrm{M}-\mathrm{H}$, random $[95 \% \mathrm{Cl}]$

\section{b}

Study or subgroup

$\frac{\text { TG }}{\text { Events }}$

\begin{tabular}{|c|c|c|}
\hline Study or subgroup & Events & Total \\
\hline Ushimaru, 2018 & 6 & 39 \\
\hline Sugiyama, 2018 & 0 & 10 \\
\hline Son, 2014 & 1 & 64 \\
\hline Nishigori, 2017 & 5 & 40 \\
\hline Kosuga, 2015 & 4 & 25 \\
\hline Ko, 2019 & 2 & 52 \\
\hline Katai, 2019 & 0 & 49 \\
\hline Jung, 2017 & 3 & 92 \\
\hline Ikeguchi, 2012 & 0 & 51 \\
\hline Hosoda, 2016 & 11 & 40 \\
\hline Hayami, 2017 & 2 & 43 \\
\hline Cho, 2018 & 0 & 38 \\
\hline Ahn, 2013 & 6 & 50 \\
\hline
\end{tabular}

Total $[95 \% \mathrm{Cl}]$

573 Total

Odds ratio Weight $\mathrm{M}-\mathrm{H}$, random $[95 \% \mathrm{Cl}]$

$0.21[0.01,4.52]$

$0.33[0.06,1.75]$

$4.10(1.30,12.93]$

$0.09[0.00,1.80]$

$2.60(0.43,15.83]$

Not estimable

$182.32[10.64,3,123.24]$

$1.00(0.14,7.38]$

$1.79[0.44,7.35]$

$30.16(1.57,577.93]$

$5.67(0.37,120.80]$

$5.29[0.60,46.38]$

$0.54[0.06,5.35]$

$0.62[0.02,16.57]$

$6.91(0.79,60.38$

$6.14(3.01,12.51]$

$0.32(0.03,3.30]$

$2.21[1.08,4.50]$

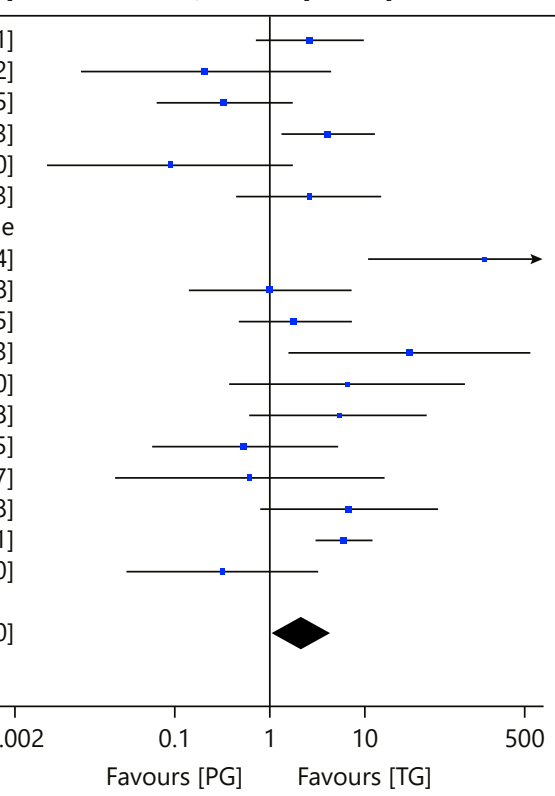

Heterogeneity: $\chi^{2}=18.91, \mathrm{df}=11(p=0.006) ; R^{2}=42 \%$

Test for overall effect: $Z=2.26(p=0.02)$

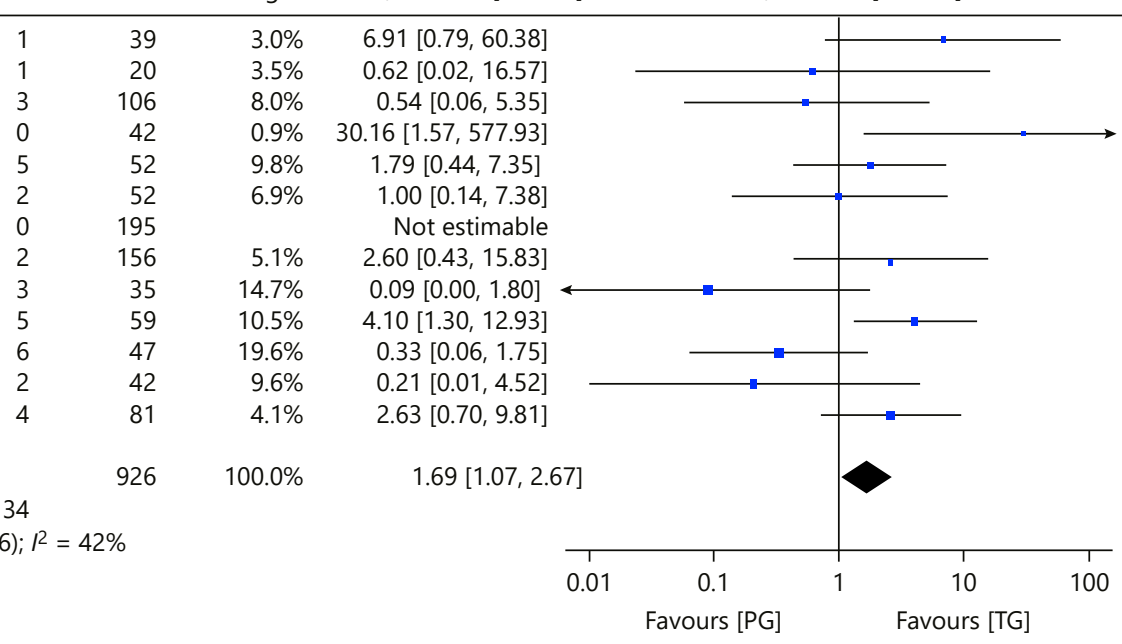

Odds ratio

C

TG

Odds ratio

Odds ratio

Study or subgroup

PG

$\overline{\text { Events Total }}$

Weight $\mathrm{M}-\mathrm{H}$, random $[95 \% \mathrm{Cl}]$

$\mathrm{M}-\mathrm{H}$, random $[95 \% \mathrm{Cl}]$

\begin{tabular}{lllllll}
\hline Cho, 2018 & 0 & 38 & 2 & 42 & $21.8 \%$ & $0.21[0.01,4.52]$
\end{tabular}

Ikeguchi, 2012

Jung, 2017

Katai, 2019

513

335

Ko, 2019

Sugiyama, 2018

0
3

3

$92 \quad 2$

35
156

156

$38.0 \% \quad 0.09[0.00,1.80]$

$13.3 \% \quad 2.60[0.43,15.83]$

Not estimable

$17.8 \% \quad 1.00[0.14,7.38]$

$9.1 \% \quad 0.62[0.02,16.57]$

Total $[95 \% \mathrm{Cl}]$

10

20

$9.1 \%$

Total events

5

500

$100.0 \%$

$0.66[0.25,1.71]$

Heterogeneity: $\chi^{2}=4.60, \mathrm{df}=4(p=0.33) ; R^{2}=13 \%$

Test for overall effect: $Z=0.86(p=0.39)$

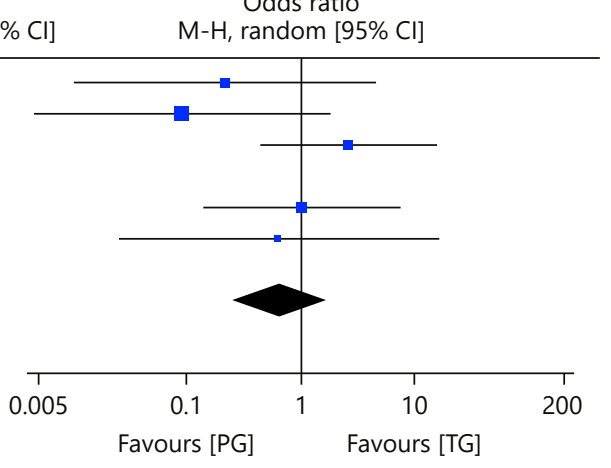

(For legend see next page.) 
The incidence of reflux symptoms (OR $=3.33$ [95\% CI: 1.85-5.99]; $p<0.001$ ) was significantly higher in the $P G$ group than in the TG group (Fig. 3a). Reflux esophagitis of 12 included studies, however, was comparable between the PG and TG groups (OR = 1.36 [95\% CI: 0.59-3.13]; $p=0.47$ ) (online suppl. Fig. 5). The heterogeneity of reflux symptom rate and reflux esophagitis between the 2 groups was significant $\left(I^{2}=21\right.$ and $70 \%$, respectively). This metaanalysis also revealed that the incidence of anastomotic stenosis between the PG and TG groups was also different $(\mathrm{OR}=2.21$ [95\% CI: 1.08-4.50]; $p=0.03)$ (Fig. 4a, b), and the heterogeneity was significant $\left(I^{2}=59 \%\right)$. In contrast, there was no significant difference between the 2 groups for detailed PG patients following DTR in terms of reflux symptoms and anastomotic stenosis $(p=0.23$ and $p=0.39$, respectively) (Table 2; Figs. 3b, 4c).

Eleven homogenous $\left(I^{2}=0.0 \%\right)$ studies $(1,439$ patients) provided data of ileus. According to the fixed-effects model, the TG group showed a higher ileus rate than the PG group (OR $=0.30$ [95\% CI: 0.20-0.78]; $p=0.007$ ). The result also revealed that patients who underwent TG had more possibility of abdominal abscess $(\mathrm{OR}=0.36$ [95\% CI: 0.19-0.69]; $p=0.002$ ) (Table 2).

\section{Long-Term Survival Outcomes}

Our result showed that the PG group was associated with a better 5-year OS relative to TG with 11 included studies ( $\mathrm{OR}=1.35$ [95\% CI: 1.03-1.77]; $p=0.03$ ) (Fig. 5a). After stratification for early gastric cancer and PG-DTR groups, however, there was no significant difference between the 2 groups (OR $=1.35$ [95\% CI: 0.59-2.45]; $p=$ 0.62 ) (Fig. 5b, c).

\section{Discussion}

To date, the extent of optimal gastric resection for PGC continues to remain controversial, and a final consensus has yet to be met. Realistically, many surgeons are now actively applying PG to PGC due to the advantages of preservation of the gastric remnant. Our study used a meta-analysis way, a total of 2,896 patients from 25 studies, to investigate how the gastrectomy type was associ-

Fig. 4 The incidence of anastomotic stenosis of gastrectomy between the PG and TG groups. a For all gastric cancer patients irrespective of stage. b For only early gastric cancer patients. c For only the PG group with DTR. PG, proximal gastrectomy; TG, total gastrectomy; DTR, double-tract reconstruction.

Proximal Gastrectomy or Total Gastrectomy, Which One Is Better? ated with perioperative complications and prognosis of PGC patients. To our best knowledge, this analysis represented the largest evaluation that targeted this issue.

Surgical resection was the preferred treatment for gastric cancer patients [46]. Our analyses indicated that the PG group showed equivalent outcomes of the operative time and estimated blood loss duration gastrectomy when compared with the TG group. The published randomized controlled study, however, demonstrated that the volume of intraoperative blood loss was obviously more by TG than the PG procedure as it was universally acknowledged [40]. A critical reason for this difference was the technical development for PG surgery nowadays. Concerning neo-/ adjuvant therapy, an essential factor for survival, there was no significant difference between the 2 groups. In addition, our study also revealed TG enabled a more completed nodal dissection, which was concordance with all published studies [47, 48]. The extent of lymphadenectomy was another important consideration when TG and PG are compared, especially the dissection of \#4d, \#5, and \#6, which are usually excluded in PG. However, Yura et al. [49] following 202 locally advanced gastric cancer patients indicated that the metastatic rate of these lymph nodes was really low (\#4d, $0.99 \%$; $\# 5,0 \%$; and $\# 6,0 \%$ ), while the nodes with high metastatic rate for PGC, like \#3, \#2, and $\# 1$, were included in PG. This may suggest that oncological safety would be ensured by PG, without the need for TG when targeting for nodal dissection.

Recently, postoperative quality of life has received significant attention in addition to oncological outcomes. This was mainly because the incidence of postgastrectomy disturbances in patients who underwent PG was high as previously reported, including some meta-analyses $[17,29,47,48,50]$. In our experience, the PG group showed a higher rate of anastomotic stenosis and reflux symptoms but similar reflux esophagitis when compared with TG. More investigations are needed to clarify this issue in future studies. Luckily, PG patients with DTR of our study did not have a higher rate for postoperative complications, including anastomotic stenosis and reflux symptoms. The esophagojejunostomy techniques, such as that done with jejunal interposition (JI) or DTR, are now thought to be alternatives to esophagogastrostomy (EG) reconstruction after PG to prevent postoperative complications [7, 51, 52]. For example, Li et al. [53] showed that there was no difference statistically in anastomotic stenosis and reflux esophagitis between laparoscopy-assisted proximal gastrectomy (LAPG) with DTR and laparoscopy-assisted total gastrectomy (LATG), which showed an optimistic prospect for PG feasibly. 


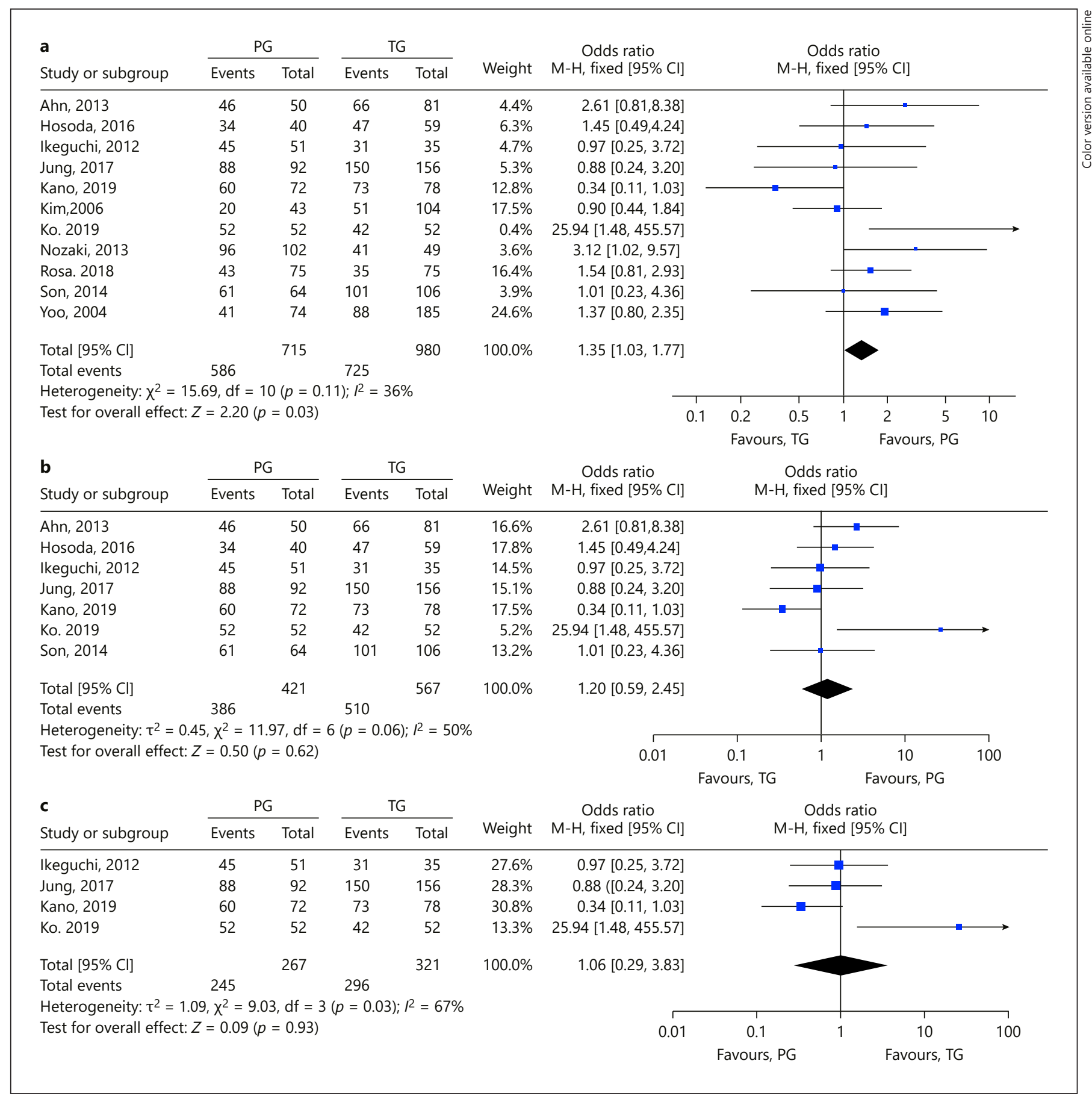

Fig. 5 The 5-year OS for PGC with PG or TG. a For all gastric cancer patients irrespective of stage. b For only early gastric cancer patients. c For only the PG group with DTR. OS, overall survival; PGC, proximal gastric cancer; PG, proximal gastrectomy; TG, total gastrectomy; DTR, double-tract reconstruction.

Shreds of evidence for the prognosis effect of PG have been inconsistent. The published "Japanese Gastric Cancer Treatment Guidelines 2014" commended that PG was only suitable for some certain early stage diseases (such as clinical T1a), while TG should be recommended for advanced PGC to achieve the standard lymph node dissections [46]. On the other hand, some recent meta-analyses showed no significant difference in long-term survival in
10

Dig Surg 2021;38:1-13

DOI: $10.1159 / 000506104$
Zhao/Ling/Chen/Shi/Chai/Ma/Zhao/ Chen 
both early and locally advanced gastric cancer between PG and TG groups in past years [17, 47, 48, 50]. Different from these meta-analyses, our study provided that PG had a prominent improved OS than TG for all gastric cancer patients irrespective of stage, while a similar 5-year OS for only early gastric cancer patients. This may suggest that the PG approach with DTR could be considered under well-established protocols for resectable PGC patients. There were some possible reasons for this survival difference. Firstly, compared with the previous metaanalyses, we have included the latest articles targeting this issue until October 2019. Ko et al. [41] even presented that 5 -year OS rates were 100 and $81.6 \%$ for PG with DTR and TG patients $(p=0.02)$, respectively. Secondly, the PG group appeared to present at an earlier stage (higher rate of pathological stage I, $p<0.05$ ) when compared with the TG group, which may have a survival bias for outcomes. Furthermore, a possible reason for the favorable survival for all patients but not in the subgroup of early stage patients was that the patients with stage II-IV cancers are more likely to be older, who would receive more benefits of stomach-function preserving of PG than TG, thus keeping a stable nutritional status [26].

Strengths and limitations should be considered when interpreting the study results. The study had several advantages. Above all, it might have the reference value as the number of this meta-analysis was the largest to date to compare the clinical outcomes between PG and TG groups. Moreover, we assessed the effect of PG on perioperative results, postgastrectomy disturbances, and long-term survival outcomes. Nevertheless, there are some limitations. Firstly, 23 of 25 studies were clinical observational trials, and only one was a clinical phase III trial. Secondly, the heterogeneities of the operation time, blood loss, number of retrieved lymph nodes, and other variables were all significant. This result may be mainly attributed to the selection bias. Thirdly, nutrition and body weight indexes after gastrectomy were not included in this meta-analysis for limited data reported in the original articles.

In conclusion, PG was associated with a visible improved long-term survival outcome for all irrespective of tumor stage, while a similar 5-year OS for only early gastric cancer patients between the 2 groups. Future randomized clinical trials of esophagojejunostomy techniques, such as DTR following PG, are expected to prevent postoperative complications and assist surgeons in the choice of surgical approach for PGC patients.

\section{Disclosure Statement}

The authors have declared no conflicts of interest.

\section{Funding Sources}

This study was funded in part by the National Key R\&D Program of China (Grant No. 2017YFC0908300).

\section{Author Contributions}

Lulu Zhao and Rui Ling contributed equally to this work. All authors made substantial contributions to the intellectual content of this paper. Yingtai Chen: concept; Lulu Zhao: design; Jinghua Chen: supervision; Fuhai Ma: resources; Anchen Shi: materials; Changpeng Chai: data collection and processing; Dongbing Zhao: analysis and interpretation; Jinghua Chen: literature search; Rui Ling and Lulu Zhao: manuscript writing; and Yingtai Chen: critical review.

\section{References}

1 Ferlay J, Colombet M, Soerjomataram I, Mathers C, Parkin DM, Piñeros M, et al. Estimating the global cancer incidence and mortality in 2018: GLOBOCAN sources and methods. Int J Cancer. 2019;144(8):1941-53.

2 Deans C, Yeo MS, Soe MY, Shabbir A, Ti TK, So JB. Cancer of the gastric cardia is rising in incidence in an Asian population and is associated with adverse outcome. World J Surg. 2011;35(3):617-24.

3 Carr JS, Zafar SF, Saba N, Khuri FR, El-Rayes BF. Risk factors for rising incidence of esophageal and gastric cardia adenocarcinoma. J Gastrointest Cancer. 2013;44(2):143-51.
4 Steevens J, Botterweck AA, Dirx MJ, van den Brandt PA, Schouten LJ. Trends in incidence of oesophageal and stomach cancer subtypes in Europe. Eur J Gastroenterol Hepatol. 2010; 22(6):669-78

5 An JY, Youn HG, Choi MG, Noh JH, Sohn TS, Kim S. The difficult choice between total and proximal gastrectomy in proximal early gastric cancer. Am J Surg. 2008;196(4):587-91.

6 Association JGC. Japanese gastric cancer treatment guidelines 2010 (ver. 3). Gastric Cancer. 2017;14(2):113-23.
7 Nozaki I, Hato S, Kobatake T, Ohta K, Kubo Y, Kurita A. Long-term outcome after proximal gastrectomy with jejunal interposition for gastric cancer compared with total gastrectomy. World J Surg. 2013;37(3):558-64.

8 Ichikawa D, Komatsu S, Kubota T, Okamoto K, Shiozaki A, Fujiwara $H$, et al. Long-term outcomes of patients who underwent limited proximal gastrectomy. Gastric Cancer. 2014; 17(1):141-5.

9 Son MW, Kim YJ, Jeong GA, Cho GS, Lee MS Long-term outcomes of proximal gastrectomy versus total gastrectomy for upper-third gastric cancer. J Gastric Cancer. 2014;14(4): $246-51$
Proximal Gastrectomy or Total Gastrectomy, Which One Is Better? 
10 Hosoda K, Yamashita K, Katada N, Moriya H, Mieno $\mathrm{H}$, Shibata T, et al. Potential benefits of laparoscopy-assisted proximal gastrectomy with esophagogastrostomy for ct1 upperthird gastric cancer. Surg Endosc. 2016;30(8): 3426-36.

11 Ikeguchi M, Kader A, Takaya S, Fukumoto Y, Osaki T, Saito H, et al. Prognosis of patients with gastric cancer who underwent proximal gastrectomy. Int Surg. 2012;97(3):275-9.

12 Kaibara N, Nishimura O, Nishidoi H, Kimura $\mathrm{O}$, Koga S. Proximal gastrectomy as the surgical procedure of choice for upper gastric carcinoma. J Surg Oncol. 2010;36(2):110-2.

13 Isobe $\mathrm{T}$, Hashimoto K, Kizaki J, Matono S, Murakami N, Kinugasa T, et al. Reconstruction methods and complications in proximal gastrectomy for gastric cancer, and a comparison with total gastrectomy. Kurume Med J. 2014;61(1-2):23-9.

14 Kitamura K, Yamaguchi T, Okamoto K, Taniguchi H, Hagiwara A, Sawai K, et al. Total gastrectomy for early gastric cancer. J Surg Oncol. 2010;60(2):83-8.

15 Erturk MS, Ciçek Y, Ersan Y, Saribeyoğlu K, Doğusoy G, Erginoz E. Analysis of clinicopathological prognostic parameters in adenocarcinoma of the gastric cardia. Acta Chir Belg. 2003;103(6):611-5.

16 Yoo CH, Sohn BH, Han WK, Pae WK. Longterm results of proximal and total gastrectomy for adenocarcinoma of the upper third of the stomach. Cancer Res Treat. 2004;36(1): 50-5.

17 Sugoor P, Shah S, Dusane R, Desouza A, Goel M, Shrikhande SV. Proximal gastrectomy versus total gastrectomy for proximal third gastric cancer: total gastrectomy is not always necessary. Langenbecks Arch Surg. 2016; 401(5):687-97.

18 Harrison LE, Karpeh MS, Brennan MF. Total gastrectomy is not necessary for proximal gastric cancer. Surgery. 1998;123(2):127-30.

19 Ying KM, Chen Z, Dang CX, Sun MC, Yan $\mathrm{GR}, \mathrm{Kan} \mathrm{BH}$, et al. Clinicopathology and survival in patients with gastroesophageal reflux after radical surgery of proximal gastric cancer. Dig Dis Sci. 2018;63(4):1035-42.

20 Zhao D, Xu H, Li K, Sun Z. Prognostic factors for patients after curative resection for proximal gastric cancer. J Huazhong Univ Sci Technol Med Sci. 2010;30(4):530-5.

21 Kim JH, Park SS, Kim J, Boo YJ, Kim SJ, Mok YJ, et al. Surgical outcomes for gastric cancer in the upper third of the stomach. World J Surg. 2006;30(10): 1870-8.

22 Stang A. Critical evaluation of the NewcastleOttawa Scale for the assessment of the quality of nonrandomized studies in meta-analyses. Eur J Epidemiol. 2010;25(9):603-5.

23 Higgins JP, Thompson SG, Deeks JJ, Altman DG. Measuring inconsistency in meta-analyses. BMJ. 2003;327(7414):557-60.

24 DerSimonian R, Laird N. Meta-analysis in clinical trials revisited. Contemp Clin Trials. 2015;45(Pt A):139-45.
25 Demets DL. Methods for combining randomized clinical trials: strengths and limitations. Stat Med. 1987;6(3):341-50.

26 Ahn SH, Lee JH, Park DJ, Kim HH. Comparative study of clinical outcomes between laparoscopy-assisted proximal gastrectomy (LAPG) and laparoscopy-assisted total gastrectomy (LATG) for proximal gastric cancer. Gastric Cancer. 2013;16(3):282-9.

27 Cho M, Son T, Kim HI, Noh SH, Choi S, Seo WJ, et al. Similar hematologic and nutritional outcomes after proximal gastrectomy with double-tract reconstruction in comparison to total gastrectomy for early upper gastric cancer. Surg Endosc. 2018;33(6):1757-68

28 Hayami M, Hiki N, Nunobe S, Mine S, Ohashi $\mathrm{M}$, Kumagai $\mathrm{K}$, et al. Clinical outcomes and evaluation of laparoscopic proximal gastrectomy with double-flap technique for early gastric cancer in the upper third of the stomach. Ann Surg Oncol. 2017;24(6):1635-42.

29 Ichikawa D, Komatsu S, Okamoto K, Shiozaki A, Fujiwara H, Otsuji E. Evaluation of symptoms related to reflux esophagitis in patients with esophagogastrostomy after proximal gastrectomy. Langenbecks Arch Surg. 2013; 398(5):697-701.

30 Jung DH, Lee Y, Kim DW, Park YS, Ahn SH, Park DJ, et al. Laparoscopic proximal gastrectomy with double tract reconstruction is superior to laparoscopic total gastrectomy for proximal early gastric cancer. Surg Endosc. 2017;31(10):3961-9.

31 Kondoh Y, Okamoto Y, Morita M, Nabeshima K, Nakamura K, Soeda J, et al. Clinical outcome of proximal gastrectomy in patients with early gastric cancer in the upper third of the stomach. Tokai J Exp Clin Med. 2007; 32(2):48-53.

32 Kosuga T, Ichikawa D, Komatsu S, Okamoto $\mathrm{K}$, Konishi H, Shiozaki A, et al. Feasibility and nutritional benefits of laparoscopic proximal gastrectomy for early gastric cancer in the upper stomach. Ann Surg Oncol. 2015;22(Suppl 3):S929-35

33 Nishigori T, Okabe H, Tsunoda S, Shinohara H, Obama K, Hosogi H, et al. Superiority of laparoscopic proximal gastrectomy with hand-sewn esophagogastrostomy over total gastrectomy in improving postoperative body weight loss and quality of life. Surg Endosc. 2017;31:3664-72.

34 Ooki A, Yamashita K, Kikuchi S, Sakuramoto S, Katada N, Hutawatari N, et al. Clinical significance of total gastrectomy for proximal gastric cancer. Anticancer Res. 2008;28(5B): 2875-83.

35 Rosa F, Quero G, Fiorillo C, Bissolati M, Cipollari C, Rausei S, et al. Total vs proximal gastrectomy for adenocarcinoma of the upper third of the stomach: a propensity-scorematched analysis of a multicenter western experience (on behalf of the Italian Research Group for Gastric Cancer-GIRCG). Gastric Cancer. 2018;21(5):845-52.
36 Shiraishi N, Adachi Y, Kitano S, Kakisako K, Inomata $\mathrm{M}$, Yasuda K. Clinical outcome of proximal versus total gastrectomy for proximal gastric cancer. World J Surg. 2002;26(9): $1150-4$.

37 Sugiyama M, Oki E, Ando K, Nakashima Y, Saeki H, Maehara Y. Laparoscopic proximal gastrectomy maintains body weight and skeletal muscle better than total gastrectomy. World J Surg. 2018;42(10):3270-6.

38 Ushimaru Y, Fujiwara Y, Shishido Y, Yanagimoto Y, Moon JH, Sugimura K, et al. Clinical outcomes of gastric cancer patients who underwent proximal or total gastrectomy: a propensity score-matched analysis. World J Surg. 2018;42:1477-84.

39 Yoo CH, Sohn BH, Han WK, Pae WK. Longterm results of proximal and total gastrectomy for adenocarcinoma of the upper third of the stomach. Cancer Res Treat. 2004;36(1): 50-5.

40 Yoo CH, Sohn BH, Han WK, Pae WK. Proximal gastrectomy reconstructed by jejunal pouch interposition for upper third gastric cancer: prospective randomized study. World J Surg. 2005;29(12):1592-9.

$41 \mathrm{Ko} \mathrm{HJ}$, Kim KH, Lee SH, Choi CW, Kim SJ, In Choi C, et al. Can proximal gastrectomy with double-tract reconstruction replace total gastrectomy? A propensity score matching analysis. J Gastrointest Surg. 2019;24(3):516-24.

42 Asaoka R, Irino T, Makuuchi R, Tanizawa Y, Bando E, Kawamura T, et al. Changes in body weight, skeletal muscle and adipose tissue after gastrectomy: a comparison between proximal gastrectomy and total gastrectomy. ANZ J Surg. 2019;89(1-2):79-83.

43 Park JY, Park KB, Kwon OK, Yu W. Comparison of laparoscopic proximal gastrectomy with double-tract reconstruction and laparoscopic total gastrectomy in terms of nutritional status or quality of life in early gastric cancer patients. Eur J Surg Oncol. 2018;44(12): 1963-70.

44 Kano Y, Ohashi M, Ida S, Kumagai K, Nunobe S, Sano T, et al. Oncological feasibility of laparoscopic subtotal gastrectomy compared with laparoscopic proximal or total gastrectomy for CT1N0M0 gastric cancer in the upper gastric body. Gastric Cancer. 2019;22(5): 1060-8.

45 Katai H, Mizusawa J, Katayama H, Kunisaki C, Sakuramoto S, Inaki N, et al. Single-arm confirmatory trial of laparoscopy-assisted total or proximal gastrectomy with nodal dissection for clinical stage I gastric cancer: Japan Clinical Oncology Group study JCOG1401. Gastric Cancer. 2019;22(5):9991008.

46 Association JGC. Japanese gastric cancer treatment guidelines 2014 (ver. 4). Gastric Cancer. 2017;20(1):1-19.

47 Chen YC, Lu L, Fan KH, Wang DH, Fu WH. Proximal gastrectomy versus total gastrectomy for adenocarcinoma of the esophagogastric junction: a meta-analysis. J Comp Eff Res. 2019;8(10):753-66. 
$48 \mathrm{Xu} \mathrm{Y,} \mathrm{Tan} \mathrm{Y,} \mathrm{Wang} \mathrm{Y,} \mathrm{Xi} \mathrm{C,} \mathrm{Ye} \mathrm{N,} \mathrm{Xu} \mathrm{X.}$ Proximal versus total gastrectomy for proximal early gastric cancer: a systematic review and meta-analysis. Medicine. 2019;98(19): e15663.

49 Yura M, Yoshikawa T, Otsuki S, Yamagata Y, Morita S, Katai H, et al. Correction to: oncological safety of proximal gastrectomy for $\mathrm{T} 2 /$ T3 proximal gastric cancer. Gastric Cancer. 2019;22(4):906-35.
50 Wen L, Chen XZ, Wu B, Chen XL, Wang L, Yang $\mathrm{K}$, et al. Total vs. proximal gastrectomy for proximal gastric cancer: a systematic review and meta-analysis. Hepatogastroenterology. 2012;59(114):33-40.

51 Uyama I, Sugioka A, Fujita J, Komori Y, Matsui $\mathrm{H}$, Hasumi A. Completely laparoscopic proximal gastrectomy with jejunal interposition and lymphadenectomy. J Am Coll Surg. 2000;191(1):114-9.
52 Tomita R, Fujisaki S, Tanjoh K, Fukuzawa M. A novel operative technique on proximal gastrectomy reconstructed by interposition of a jejunal J pouch with preservation of the vagal nerve and lower esophageal sphincter. Hepatogastroenterology. 2001;48(40):1186-91.

53 Li S, Gu L, Shen Z, Mao D, Khadaroo PA, Su H. A meta-analysis of comparison of proximal gastrectomy with double-tract reconstruction and total gastrectomy for proximal early gastric cancer. BMC Surg. 2019;19(1):117. 